\title{
PESQUISA-AÇÃO E EDUCAÇÃO FÍSICA ESCOLAR: ANALISANDO O ESTADO DA ARTE
}

\author{
Luiz Gustavo Bonatto Rufino
}

Universidade Estadual Paulista "Júlio de Mesquita Filho", Rio Claro, São Paulo, Brasil

\section{Suraya Cristina Darido}

Universidade Estadual Paulista "Júlio de Mesquita Filho", Rio Claro, São Paulo, Brasil

\begin{abstract}
Resumo
A Educação Física escolar, atualmente, tem buscado novas formas de investigar a prática pedagógica. Assim, a pesquisa-ação apresenta-se como uma possibilidade metodológica de ação e reflexão sobre a práxis. Este trabalho objetivou analisar a produção científica da pesquisa-ação na Educação Física escolar em alguns periódicos nacionais brasileiros. Entre os anos de 2000 a 2010, encontrou-se 1485 artigos sendo 461 (31,04\%) sobre Educação Física escolar e apenas 22 artigos (1,48\% do total e 4,77\% dos de Educação Física escolar) empregaram a pesquisa-ação. Conclui-se que a pesquisa-ação como uma ferramenta de auxílio às pesquisas na área da Educação Física escolar ainda apresenta um bai xo número de investigações, sendo necessário haver mais estudos pautados nesta metodologia.
\end{abstract}

Palavras-chaves: Pesquisa qualitativa. Indicadores de Produção Científica. Técnicas de Pesquisa.

\section{Introdução}

De acordo com Bracht (1993) a pesquisa na área da Educação Física mudou a partir do final da década de 1970 devido a algumas iniciativas, elencadas pelo autor como: criação e implantação de cursos de pós-graduação, incentivo à capacidade docente, financiamento e fomento de pesquisa científica, ida de pesquisadores para o exterior, dentre outros.

O autor afirma ainda que até a década de 1970, havia um predomínio das subáreas da medicina esportiva, da fisiologia e da cineantropometria, ou seja, a Educação Física sofria uma forte influência das ciências naturais. A partir de 1980, verificou-se um crescimento do número de pesquisas das áreas pedagógica e sociocultural, influenciadas pelas ciências sociais e humanas (BRACHT, 1993).

Betti (2009) constata que a pesquisa em Educação Física escolar, a partir da década de 1980, foi marcada por uma maior produção de ensaios teóricos, estudos filosóficos, históricos e pedagógicos, bem como pesquisas na área da aprendizagem e do desenvolvimento motor. 
Apesar desse aumento, em estudo recente, Manoel e Carvalho (2011), ao realizarem um levantamento dos cursos de pós-graduação na área da Educação Física no Brasil, constataram que o maior número de docentes que orientam nesses programas, $60,7 \%$, pertence à subárea da biodinâmica, em detrimento das subáreas sociocultural com $22,52 \%$ e pedagógica com $17 \%$. Com relação às linhas de pesquisa a distribuição segue a mesma tendência: $50 \%$ da biodinâmica, $33 \%$ da sociocultural e $17 \%$ da pedagógica.

Os dados são ainda mais alarmantes quando se considera a distribuição por projetos de pesquisa uma vez que $67,4 \%$ são da biodinâmica, enquanto que $22,6 \%$ da sociocultural e aproximadamente $10 \%$ da pedagógica. Todos estes dados ilustram que, apesar das transformações ocorridas a partir da década de 1980, a pesquisa relacionada à pós-graduação da Educação Física se mantém sob forte influência da biodinâmica (MANOEL; CARVALHO, 2011).

Mesmo com a pouca valorização das pesquisas pedagógicas, o que de acordo com Manoel e Carvalho (2011) ocasiona uma série de problemas como desvalorização dos pesquisadores dessa subárea, descredenciamento de alguns pesquisadores, entre outros, é preciso considerar a inserção das pesquisas de caráter qualitativo na subárea pedagógica.

Em relação às formas de pesquisa, uma das possibilidades é a pesquisaação, definida por Thiollent (2008, p. 14) como um tipo de pesquisa de caráter social

com base empírica que é concebida e realizada em estreita associação com uma ação ou com a resolução de um problema coletivo e no qual os pesquisadores e os participantes representativos da situação ou problema estão envolvidos de modo cooperativo ou participativo.

Especificamente na Educação Física escolar, Betti (2009) aponta a necessidade de realizar investigações pautadas na prática pedagógica, o que demanda pesquisas de campo em situações reais de ensino. A pesquisa-ação é uma possibilidade de reflexão sobre a ação, podendo provocar uma mudança efetiva na prática pedagógica.

André (2003) admite a potencialidade da pesquisa-ação, sobretudo no que corresponde a reflexão da prática e a valorização de grupos sociais mais desfavorecidos, afirmando que na área da Educação, tem-se aumentado o número de pesquisas sob esta perspectiva. Nesse sentido, é importante averiguar se os pesquisadores da subárea pedagógica da Educação Física também estão ou não se apropriando dessa forma de pesquisa.

Dada a importância desse tipo de metodologia, sobretudo considerando as necessidades de reflexões e ações sobre a prática, esse estudo teve como objetivo analisar a produção científica em pesquisa-ação na área da Educação Física escolar por meio da avaliação de artigos científicos encontrados em alguns periódicos 
nacionais durante os anos de 2000 e 2010, caracterizando o "estado da arte" das pesquisas sobre a Educação Física na escola sob este referencial.

\section{Métodos}

A investigação se deu por meio da busca na base de dados online de seis periódicos nacionais reconhecidos pelo portal QUALIS/CAPES e classificados entre os extratos B1 e B4 (ano-base de referência no portal corresponde a 2009). Há outros periódicos na área, porém os escolhidos seguiram os seguintes critérios: abrangerem pesquisas da subárea pedagógica, estarem indexados entre os referidos extratos e apresentarem durante o período analisado, pelo menos um artigo sobre a pesquisa-ação. Os periódicos foram:

- Revista Brasileira de Ciências do Esporte (Colégio Brasileiro de Ciências do Esporte - CBCE);

- Revista Pensar a Prática (Universidade Federal de Goiás - UFG);

- Revista Mackenzie de Educação Física e Esporte (Universidade Presbiteriana Mackenzie - RMEFE);

- Revista Motriz (Universidade Estadual Paulista - UNESP Rio Claro);

- Revista Movimento (Universidade Federal do Rio Grande do Sul UFRGS).

- Revista Paulista de Educação Física/ Revista Brasileira de Educação Física e Esporte (Escola de Educação Física e Esporte - USP).

Para a pesquisa na base de dados foi utilizada a inclusão de duas palavraschaves: "pesquisa-ação" e "Educação Física escolar". Os artigos que apresentaram ambas os termos como palavras-chaves, ou durante o resumo ou mesmo durante o corpo do trabalho, foram considerados para a pesquisa.

Após a quantificação do número de artigos em cada um dos periódicos analisados eles foram classificados em sete categorias temáticas diferentes, identificadas por meio da análise de conteúdo de cada um dos artigos. Assim, foi possível analisar as interfaces de produção e divulgação dos resultados oriundos das publicações em pesquisa-ação na Educação Física escolar, visando identificar o "estado da arte" da produção acadêmica nacional sob esta temática.

\section{Resultados e Discussão}

Após a análise nas bases de dados online das revistas investigadas constatou-se uma baixa quantidade de publicações pautadas na pesquisas-ação sobre a Educação Física escolar. Na tabela 1 está descrito o número total de artigos, o número de artigos sobre Educação Física escolar e o número de artigos sobre pesquisa-ação encontrados em cada um dos periódicos. 
Do total de 1485 artigos encontrados durante o período analisado (2000 a 2010), foram identificados 461 artigos sobre Educação Física escolar (31,04\% do total de artigos), sendo que apenas 22 artigos baseavam-se na pesquisa-ação, valor correspondente a $1,48 \%$ do total de artigos encontrados durante este período e $4,77 \%$ do total de artigos considerando-se apenas os artigos sobre Educação Física escolar.

Evidenciou-se também o caráter de "novidade" da pesquisa-ação na Educação Física, sendo relativamente recentes uma vez que o primeiro artigo remete ao ano de 2002. Isso evidencia que a preocupação com investigações que perpassem novas formas de se conceber a prática educativa é algo recente na área.

Por outro lado, deve-se ressaltar que na Educação de maneira geral, a pesquisa-ação é uma forma de pesquisa mais antiga. Para André (2003, p. 31) "os livros de pesquisa ação da década de 1950 descrevem essa metodologia como uma ação sistemática e controlada desenvolvida pelo próprio pesquisador". Talvez a demora da área da Educação Física escolar em reconhecer as potencialidades desta forma de investigação se deu pelo próprio amadurecimento da área, sobretudo a partir da década de 1980 quando se passou a se refletir sobre novas formas de se pensar a prática pedagógica.

Tabela 1 - Número de artigos no total, sobre Educação Física escolar e sobre pesquisa-ação em cada um dos periódicos analisados

\begin{tabular}{|c|c|c|c|}
\hline PERIÓDICO & $\begin{array}{l}\mathrm{N}^{\circ} \text { TOTAL DE } \\
\text { ARTIGOS } \\
\text { (entre os anos de } \\
2000 \text { a 2010) }\end{array}$ & $\begin{array}{c}\text { No TOTAL DE }^{\circ} \text { TOLOS SO- } \\
\text { ARTIGOSO EFE* } \\
\text { BRE }\end{array}$ & $\begin{array}{c}\text { No DE ARTIGOS }^{\circ} \\
\text { QUE EMPREGA- } \\
\text { RAM A PES- } \\
\text { QUISA-AÇÃO NA } \\
\text { EFE* }\end{array}$ \\
\hline$\overline{\text { RBCE }}$ & $275(18,51 \%)$ & $44(9,54 \%)$ & $3(13,63 \%)$ \\
\hline $\begin{array}{l}\text { PENSAR A } \\
\text { PRÁTICA }\end{array}$ & $127(8,55 \%)$ & $116(25,16 \%)$ & $1(4,55 \%)$ \\
\hline RMEFE & $127(8,55 \%)$ & $44(9,54 \%)$ & $3(13,63 \%)$ \\
\hline MOTRIZ & $366(24,65 \%)$ & $129(27,98 \%)$ & $9(40,91 \%)$ \\
\hline MOVIMENTO & $310(20,88 \%)$ & $96(20,83 \%)$ & $5(22,73 \%)$ \\
\hline RPEFE/RBEFE & $280(18,86 \%)$ & $32(6,95 \%)$ & $1(4,55 \%)$ \\
\hline TOTAL & $1485(100 \%)$ & $461(31,04 \%)$ & $\begin{array}{c}22(1,48 \% * *)- \\
(4,77 \% * * *)\end{array}$ \\
\hline
\end{tabular}

Legenda: Número de artigos no total, na Educação Física escolar e que empregaram a pesquisa-ação nas seis revistas analisadas. RBCE: Revista Brasileira de Ciências do Esporte; PENSAR A PRÁTICA: Revista Pensar a Prática; RMEFE: Revista Mackenzie de Educação Física e Esporte; MOTRIZ: Motriz Revista de Educação Física; MOVIMENTO: Revista Movimento. RPEFE/RBEFE: Revista Paulista de Educação Física e Esporte/ Revista Brasileira de Educação Física e Esporte. 
*EFE: Educação Física escolar.

** 1,48\%: em comparação ao número total de artigos.

***4,77\%: em comparação com os artigos sobre Educação Física escolar.

Ressalta-se, como afirma Pereira (1998) que a pesquisa-ação é um movimento difundido em países como Inglaterra, Austrália, Canadá, Alemanha, EUA e outros. No Brasil, a perspectiva do professor enquanto pesquisador tem-se intensificado nos últimos anos, sobretudo em algumas pesquisas da área da Educação.

O baixo número de publicações encontradas relaciona-se, em partes, com a relativa atualidade na produção acadêmica da área da Educação Física. Além disso, a falta de tradição em conceber o professor enquanto pesquisador da sua própria prática pode também ser um possível fator para a escassa produção acadêmica nesta perspectiva.

De acordo com Barbier (2007) na pesquisa-ação há uma ação deliberada de transformação da realidade, possuindo dois objetivos: transformar a realidade e produzir conhecimentos relativos a essas transformações. Pode-se aventar como uma das possíveis razões para o baixo número de artigos empregando a pesquisaação o domínio ainda presente da concepção biodinâmica e o emprego de metodologias quantitativas. Essa perspectiva exerce forte domínio nas políticas de pesquisa e pós-graduação na área, como nas agências de fomento, formatando um certo olhar sobre como devem ser as pesquisas, inclusive na Educação Física escolar brasileira.

André (2003) admite que a pesquisa-ação é uma tendência fortemente relacionada com a aproximação entre sujeito e objeto pesquisado. Partindo dessa visão, Betti (2009) considera a pesquisa-ação a melhor alternativa para articular o projeto da Educação Física escolar, intitulado pelo autor como a apropriação crítica da cultura corporal de movimento com a meta da ciência que é produzir conhecimento no confronto com o mundo. $\mathrm{O}$ autor enfatiza o potencial formativo da pesquisa-ação na Educação Física escolar enquanto possibilidade de reflexão sobre a prática, sendo necessária a busca por concepções inovadoras de pesquisa.

A partir da análise de cada uma das produções científicas encontradas foi possível organizá-las em categorias temáticas de acordo com a frequência de aparição (representadas em forma de porcentagem), concedida por meio dos resultados da análise de conteúdo realizada. As categorias temáticas e suas respectivas frequências podem ser visualizadas no gráfico 1 . Ressalta-se que um mesmo artigo poderia estar em mais de uma categoria temática.

As categorias que mais apareceram, com a frequência de $27 \%$, foram: "intervenção pedagógica" e "estratégias de ensino". Em "intervenção pedagógica" foram alocados os estudos que retrataram de maneira efetiva, formas de se pesquisar a práxis pedagógica em situações reais de ensino e aprendizagem, dando "voz" aos "atores" desse processo, os professores que estão ativamente intervindo nas escolas. 
Gráfico 1 - Educação Física escolar e pesquisa-ação: categorias temáticas

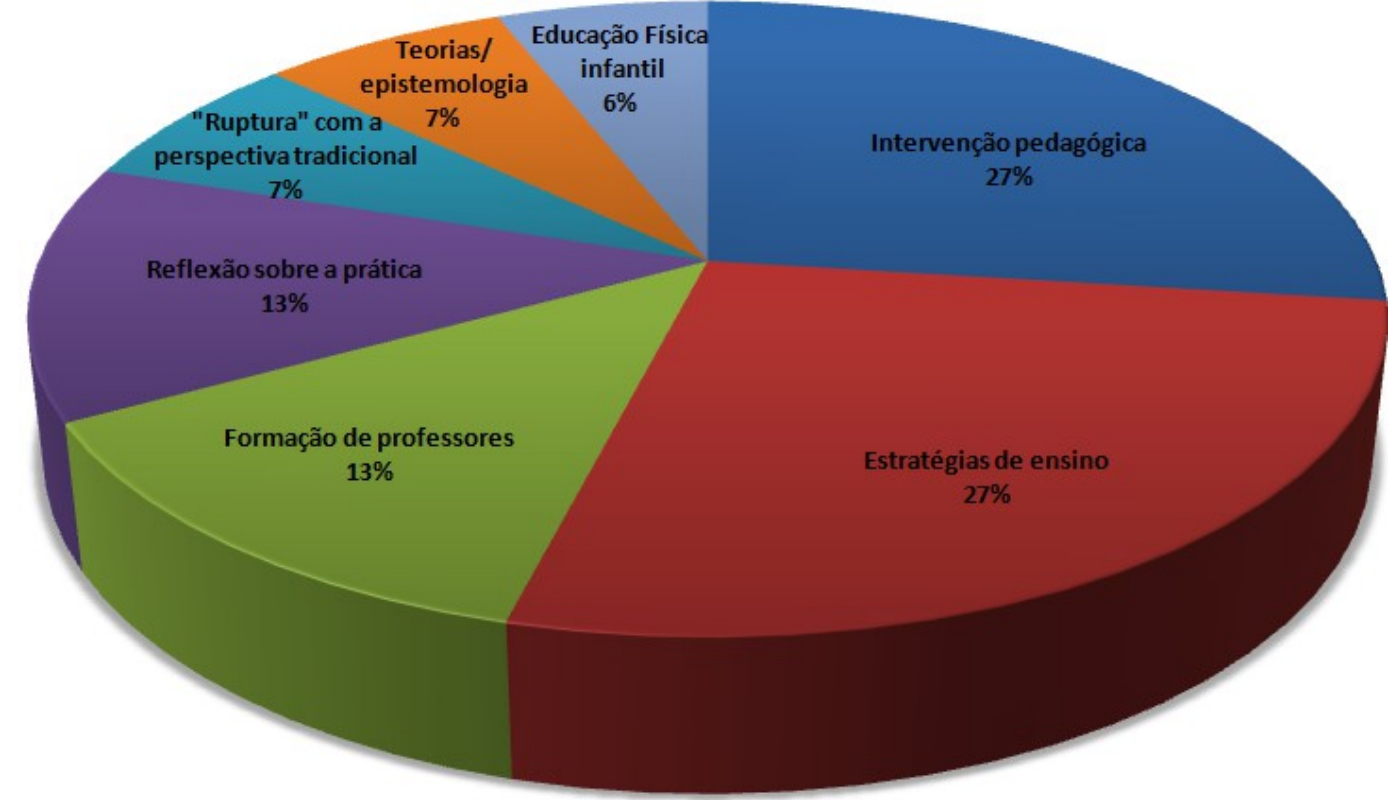

Em "estratégias de ensino", foram categorizados os estudos que enfatizaram questões relacionadas às possibilidades de utilização de diferentes formas de auxílio à prática pedagógica, sendo avaliadas pela metodologia da pesquisa-ação. Nesta perspectiva, a utilização da estratégia de "jogos e brincadeiras" se destaca com $12,72 \%$ de frequência de aparição. Estas categorias evidenciam o potencial da pesquisa-ação e como esta ferramenta metodológica está sendo utilizada nas pesquisas em Educação Física escolar.

Com 13\% de frequência de aparição houve duas categorias temáticas: "reflexão sobre a prática" e "formação de professores". Em "reflexão sobre a prática" foram identificados os estudos que enfatizaram a possibilidade da pesquisa-ação em contribuir para uma ação reflexiva acerca da prática pedagógica, inserindo-a enquanto meio de organizar o trabalho docente para que o professor possa também ser pesquisador de sua práxis.

Nesta perspectiva, Thiollent (2008) afirma que a pesquisa-ação é um método ou uma estratégia de pesquisa que agrega várias técnicas da pesquisa social, estabelecendo uma estrutura coletiva, participativa e ativa. Da mesma forma, Betti (2009, p. 322) admite: "a pesquisa-ação é um delineamento de pesquisa cujo objetivo é, no contexto de um projeto político-pedagógico, produzir conhecimentos sobre a prática pedagógica".

Sobre "formação de professores" foram agregados os estudos que priorizaram a perspectiva da formação profissional seja ela inicial ou continuada e como a pesquisa-ação pode ser uma perspectiva interessante dentro desta concepção. Sen- 
do assim, alguns estudos nacionais relataram pesquisas-ações em caráter de cursos de formação, como o proposto por Bracht et al. (2002), por exemplo, que desenvolveu uma pesquisa-ação em um curso de pós-graduação em nível de especialização.

No entanto, mesmo sendo necessário construir novas formas de se avaliar a pesquisa-ação na Educação Física, Betti (2009) alerta para o risco de se considerar a pesquisa-ação a única estratégia para os programas de Educação continuada de docentes, ou para sua formação inicial. Na verdade, a pesquisa-ação deve ser concebida como mais uma possibilidade de pesquisa e reflexão.

Finalmente, com menor frequência de aparição destacam-se as seguintes categorias: "ruptura com a perspectiva tradicional" e "teorias/ epistemologia" com 7\% de frequência cada e "Educação Física infantil", com 6\%. Em "rupturas com a perspectiva tradicional" inserem-se os estudos que, de alguma forma, retrataram a necessidade de se conceber novas formas de se realizar pesquisas no âmbito da Educação Física escolar, tendo em vista a importância de se considerar de maneira mais sistemática a relação teoria e prática na área.

Para Thiollent (2008), atualmente há maior disponibilidade na realização de pesquisa-ação no âmbito educacional devido às desilusões de muitos profissionais com métodos de pesquisa tradicionais. $\mathrm{O}$ autor considera a pesquisa-ação como uma orientação destinada ao estudo e à intervenção em situações reais, se apresentando como alternativa, não devendo ser considerada como uma forma de substituição das pesquisas tradicionais, também importantes (Thiollent, 2008).

Bracht et al. (2002) admite que a pesquisa-ação não deve ser compreendida como a "panaceia dos males da educação brasileira", devendo estar atrelada a outras estratégias que visam propor o trabalho coletivo organicamente articulado para que seja possível vinculá-lo com a concepção de professor pesquisador e reflexivo.

Em "teorias/ epistemologia" foram classificados os estudos que abordaram, em seu bojo, questões sobre o debate teórico da pesquisa-ação e suas concepções acerca das questões ligadas à epistemologia desta concepção e sua forma de olhar para a produção do conhecimento. De acordo com Betti (2009) o que é "rigoroso" e "sistemático", e o que é "tradição científica" não decorrem de conceitos universais e imutáveis, e deve ser objeto de debate. $\mathrm{O}$ autor reconhece ainda a necessidade de debate epistemológico e metodológico na Educação Física brasileira.

Por fim, "Educação Física infantil" destacou os estudos que contemplaram especificamente este nível de ensino, o qual foi o que mais apresentou pesquisas utilizando-se da pesquisa-ação. Para Freire e Santana (2007), por exemplo, a pesquisa-ação é uma possibilidade que os professores possuem para investigar sua própria atuação pedagógica, uma vez que os conhecimentos sobre a prática pedagógica lúdica emergem do cotidiano das aulas e são produzidos por todos que protagonizam a cena educacional. É importante que haja ainda mais pesquisa-ação neste nível de ensino, considerando as especificidades que o reveste, porém, é 
emergente a realização de pesquisa-ação em outros níveis de ensino, como o Fundamental e Médio para que sejam avaliadas suas potencialidades.

\section{Considerações Finais}

Com o objetivo de analisar a produção científica em pesquisa-ação na subárea pedagógica da Educação Física por meio da avaliação de artigos científicos encontrados em seis periódicos nacionais durante os anos de 2000 e 2010, este trabalho buscou caracterizar o estado da arte da pesquisa-ação na Educação Física brasileira.

Embora algumas pesquisas na Educação Física escolar utilizem esta ferramenta metodológica, comparadas com outras formas mais tradicionais, a produção acadêmica ainda é incipiente no que corresponde ao baixo número de artigos encontrados $(1,48 \%)$ do total. Considerando-se apenas os artigos referentes à Educação Física escolar, os artigos baseados na pesquisa-ação corresponderam a 4,77\% do total. Sendo assim, faz-se necessário haver mais pesquisas que investiguem a Educação Física escolar utilizando-se o referencial da pesquisa-ação de forma mais aprofundada, para que seja possível contextualizar suas potencialidades e limitações durante os processos de ensino e aprendizagem.

Segundo Barbier (2007), se por muito tempo o papel da ciência foi descrever, explicar e prever os fenômenos, impondo ao pesquisador ser um observador neutro e objetivo, a pesquisa-ação adota um encaminhamento oposto pela sua finalidade: servir de instrumento de mudança social, postulando que não se pode dissociar a produção de conhecimentos dos esforços feitos para levar à transformação.

Betti (2009, p. 324) afirma que negar o conhecimento científico é subtrair ao professor uma importante fonte de informação, contudo, "aprisioná-lo nos limites da ciência é empobrecer a prática pedagógica, que é sempre mais rica e complexa do que a mais imaginativa teoria científica".

Portanto, a pesquisa-ação pode ser uma ferramenta oportuna de produção de conhecimento que seja aplicável na prática pelo professor de Educação Física na escola. Entretanto, deve-se ressaltar que, conforme afirmou Barbier (2007, p. 40): "estamos longe de uma pesquisa-ação em conformidade com nossas aspirações".

Ressalta-se ainda que o número de artigos encontrados durante o período analisado sobre Educação Física escolar, 31,04\%, não reflete o número de artigos em uma concepção qualitativa uma vez que muitos artigos investigados que abordaram a temática pedagógica o fizeram em uma perspectiva tradicional/ quantitativa.

A Educação Física escolar ainda não se apropriou de modo significativo das possibilidades da pesquisa-ação enquanto ferramenta de aproximação entre conhecimento e práxis pedagógica, entre rigor metodológico e flexibilidade para a 
intervenção eficiente e, principalmente, entre produção de conhecimento voltado a dar voz e expressão às minorias sociais, permitindo que desigualdades possam ser equiparadas, mesmo que para isso, seja necessário ainda um longo caminho.

\title{
ACTION-RESEARCH AND SCHOOL PHYSICAL EDUCATION: ANALYZING THE STATE OF ART
}

\begin{abstract}
The School Physical Education, nowadays, has sought new ways to investigate the pedagogical practice. In this context, action-research is presented as a methodological possibility of action and reflection about the praxis. This study aimed to analyze the scientific production of action-research in Physical Education in some national Brazilian journals. Between the years 2000 to 2010, it was found 1485 articles, 461 (31.04\%) about Physical Education and only 22 articles $(1.48 \%$ of the total number and $4.77 \%$ of the number of Physical Education articles) applied action-research. It is concluded that action-research as a tool to aid research in Physical Education still has a low number of investigations, being necessary more studies based on this methodology.

Keywords: Qualitative Research. Scientific Publication Indicators. Investigative Techniques.

\section{INVESTIGACIÓN-ACCIÓN Y ESCUELA DE EDUCACIÓN FÍSICA: ANÁLISIS DEL ESTADO DEL ARTE}

\section{Resumen}

La educación física en la actualidad, ha buscado nuevas formas de investigar la práctica docente. Así, la investigación-acción se presenta como una posibilidad metodológica de la acción y la reflexión sobre la praxis. Este estudio tuvo como objetivo analizar la producción científica de la investigación-acción en educación física en algunas revistas nacionales brasileñas. Entre los años 2000 a 2010, encontramos los artículos 1485 y 461 $(31,04 \%)$ en la educación física y 22 artículos (1,48\% del total y 4,77\% de la Educación Física) la investigación-acción. Se concluye que la investigación-acción como una herramienta para ayudar a la investigación en Educación Física aún tiene un bajo número de investigaciones, siendo necesario realizar más estudios sobre la base de esta metodología. Palabras clave: Investigación Cualitativa. Indicadores de Produción Científica. Técnicas de Investigación.

\section{Referências}

ANDRÉ, M. E. D. A. Etnografia da prática escolar. Campinas: Papirus, 2003.

BARBIER, R. A Pesquisa-Ação. Brasília: Liber, 2007.

BETTI, M. Educação Física escolar: ensino e pesquisa-ação. Ijuí: Unijuí, 2009. 
BRACHT, V. Educação Física/Ciências do esporte: que Ciência é Essa?. Revista Brasileira de Ciências do Esporte, Campinas, v. 14, n. 3, p. 111- 118. 1993.

BRACHT, V. et al. A prática pedagógica em Educação Física: a mudança a partir da pesquisa-ação. Revista Brasileira de Ciências do Esporte, Campinas, v. 23, n. 2, p. 9-29. 2002.

FREIRE, J. B.; SANTANA, G. M. L. Relações sociais no desenvolvimento da imaginação por meio de jogos. Motriz, Rio Claro, v. 13, n. 4, p. 249-258, out./dez., 2007.

MANOEL, E. de J.; CARVALHO, Y. M. de. Pós-graduação na educação física brasileira: a atração (fatal) para a biodinâmica. Educação e Pesquisa, São Paulo, v. 37, n. 2, p. 389-406, mai./ago., 2011.

PEREIRA, E. M. de A. Professor como pesquisador: o enfoque da pesquisa-ação na prática docente. In: SERALDI, C. M. G.; FIORENTINI, D.; PEREIRA, E. M. de A. (Orgs.). Cartografias do trabalho docente: professor(a)- pesquisador(a). Campinas: Mercado das Letras; ALB, 1998. p. 153-181.

THIOLlENT, M. Metodologia da pesquisa-ação. São Paulo: Cortez, 2008.

Recebido em: 14/05/2012

Revisado em: 28/10/2012

Aprovado em: 14/02/2013

Endereço para correspondência:

surayacd@rc.unesp.br

Suraya Cristina Darido

Universidade Estadual Paulista Júlio de Mesquita Filho,

Instituto de Biociências de Rio Claro, Departamento de Educação Física.

Av. 24 A, No 1515

Bela Vista

13506-000 - Rio Claro, SP - Brasil 